\title{
Perioperative nocturnal hypoxemia matters in surgical patients with obstructive sleep apnea
}

\author{
Frances Chung, MBBS $\cdot$ Matthew T. V. Chan, MBBS $\cdot$ Pu Liao, MD
}

Received: 8 September 2016/ Accepted: 12 October 2016/Published online: 20 October 2016

(C) Canadian Anesthesiologists' Society 2016

\section{To the Editor,}

Obstructive sleep apnea (OSA) is a common co-morbidity in surgical patients, with a prevalence of $7-10 \% .{ }^{1,2}$ Patients with OSA - especially those with undiagnosed and untreated OSA - are at increased risk of postoperative complications. ${ }^{1-3}$ The risk of cardiovascular complications, primarily cardiac arrest and shock, was significantly higher in patients with undiagnosed OSA than in those with diagnosed OSA who had been given a prescription for continuous positive airway therapy. ${ }^{4}$

The exact mechanism for the increased risk of postoperative complications associated with OSA is unknown. In a recent letter to the Journal, Deflandre et al. showed that surgical patients with OSA of similar severity may have different degrees of hypoxia. ${ }^{5}$ Among their patients with severe OSA (i.e., apnea hypopnea index $[\mathrm{AHI}]>30$ events per hour), $33 \%$ had no or only mild nocturnal hypoxia [defined as an oxygen desaturation index (ODI) of $<5$ or $5-15$ events per hour], and $29 \%$ and $38 \%$ had moderate or severe nocturnal hypoxia (ODI 15-30 or $>$ 30 events per hour). ${ }^{5}$ This variation in the severity of

This letter is accompanied by a reply. Please see Can J Anesth 2017; 64: this issue.

F. Chung, MBBS $(\bowtie) \cdot$ P. Liao, MD

Department of Anesthesia, Toronto Western Hospital, University Health Network, University of Toronto, Toronto, ON, Canada

e-mail: Frances.chung@uhn.ca

M. T. V. Chan, MBBS

Department of Anesthesia and Intensive Care, The Chinese University of Hong Kong, Prince of Wales Hospital, Hong Kong, People's Republic of China hypoxia may be related to different OSA phenotypes and variations in the underlying OSA pathophysiology. ${ }^{6}$

Deflandre et al. proposed the hypothesis that hypoxiamediated inflammatory modifications could increase the risk of postoperative complications. ${ }^{5}$ At present, however, there are no direct data indicating that hypoxia-mediated inflammation in a patient with OSA increases the risk of postoperative complications. Indirect data, however, show that preoperative nocturnal hypoxia is associated with increased postoperative complications.

We have shown that ODI is a sensitive, specific predictor of OSA. In 573 patients $(37.1 \%$ with moderate/severe OSA and an AHI of $>15$ events per hour), preoperative nocturnal hypoxia was associated with the incidence of postoperative complications. ${ }^{7}$ In the same study, among patients with a mean oxygen saturation $\left(\mathrm{SpO}_{2}\right)$ of $<92.7 \%$, an ODI of $>28.5$ events per hour, and/ or an accumulated overnight duration of oxygen saturation of $<90 \%,>7.2 \%$ were at higher risk for postoperative adverse events. ${ }^{7}$ In addition, in a longitudinal study (5.3 years) of 10,701 patients with OSA, sudden cardiac death was associated with an AHI of $>20$ events per hour [hazard ratio (HR), 1.60], a mean nocturnal $\mathrm{SpO}_{2}$ of $<93 \%$ (HR, 2.93), and a lowest nocturnal $\mathrm{SpO}_{2}$ of $<78 \%$ (HR, 2.60) (all $P<0.001$ ). ${ }^{8}$ The lowest nocturnal $\mathrm{SpO}_{2}$ predicted an $81 \%$ increase in sudden cardiac death. ${ }^{8}$

Various potential mechanisms for increased cardiovascular complications have been proposed, including increased vascular sympathetic activity and serum catecholamines, cardiac autonomic dysfunction, and an ineffective arousal mechanism related to impaired chemosensitivity. ${ }^{8}$ If the hypothesis that nocturnal hypoxia plays a key role in mediating complications is confirmed, supplemental oxygen and/or continuous positive airway therapy during the postoperative period may prevent 
hypoxic episodes and thus reduce sudden cardiac death. ${ }^{9}$ At present, limited evidence from our previous study ${ }^{7}$ supports the idea that nocturnal hypoxia may play a key role in mediating complications. Further trials are needed to investigate this hypothesis.

Conflicts of interest Dr. Frances Chung: STOP-Bang is proprietary to the University Health Network. Grant support from ResMed Foundation and Acadia.

Editorial responsibility This submission was handled by Dr. Hilary P. Grocott, Editor-in-Chief, Canadian Journal of Anesthesia.

\section{References}

1. Mokhlesi B, Hovda MD, Vekhter B, Arora VM, Chung F, Meltzer $D O$. Sleep-disordered breathing and postoperative outcomes after elective surgery: analysis of the nationwide inpatient sample. Chest 2013; 144: 903-14.

2. Memtsoudis SG, Stundner $O$, Rasul R, et al. The impact of sleep apnea on postoperative utilization of resources and adverse outcomes. Anesth. Analg 2014; 118: 407-18.
3. Opperer M, Cozowicz C, Bugada D, et al. Does obstructive sleep apnea influence perioperative outcome? A qualitative systematic review for the Society of Anesthesia and Sleep Medicine Task Force on preoperative preparation of patients with sleep-disordered breathing. Anesth Analg 2016; 122: 1321-34.

4. Mutter TC, Chateau D, Moffatt M, Ramsey C, Roos LL, Kryger M. A matched cohort study of postoperative outcomes in obstructive sleep apnea: could preoperative diagnosis and treatment prevent complications? Anesthesiology 2014; 121: 707-18.

5. Deflandre EP, Bonhomme VL, Brichant JF, Joris JL. What mediates postoperative risk in obstructive sleep apnea: airway obstruction, nocturnal hypoxia, or both? Can J Anesth 2016; 63: 1104-5.

6. Subramani $Y W$, Kushida CA, Malhotra A, Chung F. Understanding phenotypes of obstructive sleep apnea: applications in anesthesia, surgery, and perioperative medicine. Anesth Analg 2016; in press.

7. Chung F, Zhou L, Liao P. Parameters from preoperative overnight oximetry predict postoperative adverse events. Minerva Anestesiol 2014; 80: 1084-95.

8. Gami AS, Olson EJ, Shen WK, et al. Obstructive sleep apnea and the risk of sudden cardiac death: a longitudinal study of 10,701 adults. J Am Coll Cardiol 2013; 62: 610-6.

9. Nagappa M, Mokhlesi B, Wong J, Wong DT, Kaw R, Chung F. The effects of continuous positive airway pressure on postoperative outcomes in obstructive sleep apnea patients undergoing surgery: a systematic review and meta-analysis. Anesth Analg 2015; 120: 1013-23. 